\title{
TECHNOLOGIES OF USING ENERGY HARVESTING SYSTEMS IN MOTOR VEHICLES - ENERGY FROM SUSPENSION SYSTEM
}

\author{
Jacek Caban \\ Lublin University of Technology, Poland \\ j.caban@pollub.pl
}

\begin{abstract}
The automotive sector is characterized by a high energy demand related to the use of fuels and maintenance of vehicles in technical readiness. Currently, more and more often solutions are sought that will save energy and cause less losses in the so-called wasted energy. Most of the energy, about $60 \%$, generated from internal combustion engines is dissipated despite the constant efforts of engine manufacturers to improve their economic and ecological properties. In addition, energy is generated in road vehicles from other components, e.g., the suspension system. As a result, systems are being sought to recover some of this energy to power certain sensors and vehicle systems. This study presents energy recovery systems in road vehicles. Based on a literature study of the presented research of various research centres, it was noticed that there is a huge potential in the recovery of energy lost in the vehicle suspension systems. Research shows that it is possible to obtain a regenerative power value of several hundred watts, which depends on the type of vehicle and the road type on which the vehicle is traveling. An area that has been little explored, but also has energy potential, is the recovery of energy from the internal combustion engine suspension system in the engine compartment. This article presents technological solutions for the energy harvesting from the vehicle suspension system and preliminary studies of the potential energy recovery from the suspension of the 4-cylinder in-line diesel engine in an off-road vehicle. It is also important that energy recovery systems have application potential in traditional vehicles powered by internal combustion engines, as well as modern vehicles with hybrid or electric drive.
\end{abstract}

Keywords: vibration energy, wasted energy, micro sensors, road vehicles.

\section{Introduction}

The constantly growing volume of transport performance of individual road transport and the high concentration of transport in general have a very negative effect on environmental pollution and humanity as a whole [1]. Besides, road transport carries certain risks, the most important of which are road accidents [2], the phenomenon of transport congestion [3; 4], noise [5] and exhaust emissions to the environment [6-8]. The transport sector consumes a significant amount of energy and is at the same time a major source of environmental pollution [9]. The energy intensity of transport is a current topic worldwide. The use of alternative fuels is one of the main solutions currently allowing the reduction of pollutant emissions [10]. Literature information on the subject of the research of various alternative fuels was found, e.g., in [11-15], and about reduction in the consumption of lubricating oils and plastic lubricants $[16 ; 17]$. Among others, for economic and rural development reasons, there is a growing interest in plant-derived fuels (biodiesel) [18-20] and LPG or CNG gas fuels $[9 ; 10 ; 15 ; 21 ; 22]$. The automotive industry is currently undergoing a huge transformation related to the development of new propulsion systems (hybrid and electric), while improving internal combustion engines [23-29]. From a local point of view, the operation of electric vehicles can be considered environmentally friendly, since the operation itself does not produce GHG [26]. Electric car does not supply all the electric energy obtained from the electric network to the wheels in the form of mechanical energy [25]. Unfortunately, during such transformation, a part of this energy is lost, similar to a hybrid system. Nevertheless, it seems that, globally, hybrid and electric drives are more environmentally friendly than internal combustion engines.

The development of piston internal combustion engines manifests itself particularly in the improvement of fuel supply systems [27], exhaust gas treatment systems and diagnostic systems (OBD and OBDII) [30]. Many researchers use methods of vibration signal analysis, such as Fourier transform and wavelet transform [31;32], and the Hilbert transform [33; 34], or neural networks [35] for detecting defects in rotating systems. In the works $[31 ; 32 ; 36]$, a vibration signal was used to analyse the technical condition of the gears of the transmission. In turn, in $[37 ; 38 ; 39]$ such signals were used in the diagnostics of vehicle suspension systems. Safety, handling and road stability are guaranteed by appropriate vehicle suspension, consisting of a springing element and a damping element [40].

The automotive sector is characterized by a high energy demand related to the use of fuels and maintenance of vehicles in technical readiness. Therefore, reducing energy losses in individual vehicles 
and the entire transport sector is becoming imperative. For this reason, more and more attention is paid to the management of energy wasted in motor vehicles. It can be thermal energy [41; 42], regenerative braking energy [23; 43; 44], from suspension system or little used vibration energy coming from the suspension of the internal combustion engine [45]. Energy harvesting is a process of capturing these small amounts of wasted or by product energy, which otherwise gets lost and converting it into useful electrical energy [46].

In this article, on the basis of a literature study, possibilities of the damped recovery energy from the vehicle suspension system and combustion engine suspension system are presented. The paper presents preliminary test results for an off-road vehicle powered by a 4-cylinder in-line diesel engine.

\section{Research directions - review of solutions and discussion}

Vibration-based energy conversion, called piezoelectric harvesting, has significant advantages over other forms of renewable energy, including low initial investment and less complicated wiring [47]. Piezoelectric energy harvesting has been identified as a candidate for low power devices, such as portable charging devices [48], wireless electronic devices [49] and various types of sensors [50]. Wireless sensors include, e.g., strain gauges, accelerometers and thermocouples equipped with radio transmitting electronics [51]. The recovered energy can be used to power some on-board equipment or electrical sensors that monitor various functions in the vehicle.

Simultaneously with the development of energy management technology in the drive system [52] and braking energy recovery [53] in application, more and more attention is paid to the technology of harvesting energy from vehicle suspension vibrations [54; 55], since only 12-30\% of fuel energy is used to drive the car to overcome the resistance from road friction and air drag [56], and one major loss is vibration dissipation in the shock absorber [37]. As demonstrated by Zuo and Zhang [57], 100-400 W average power is available from the suspension at $96.5 \mathrm{~km} / \mathrm{h}$ on $\mathrm{B}$ and $\mathrm{C}$ class roads for a middle-sized vehicle. According to Zhang et al. [58], based on the Audi AG tests, it is possible to obtain an average power of approx. $150 \mathrm{~W}$. For a passenger car driving on newly paved German highways, it is $3 \mathrm{~W}$, while $613 \mathrm{~W}$, on a rugged country road. Li et al., [59] show that a maximum of $248.8 \mathrm{~W}$ instantaneous power with a mean of $114.1 \mathrm{~W}$ can be harvested and a maximum of $38.81 \%$ energy harvesting efficiency can be achieved using the optimal load resistance $(7.5 \Omega)$ at a harmonic excitation with the amplitude of 8 $\mathrm{mm}$ and the frequency of $2 \mathrm{~Hz}$. In automobiles, harvesting the dissipated kinetic energy during the damping events could provide fuel saving by $2-10 \%$ of the total automobile fuelling [38]. Fig. 1 shows the fuel saving possibilities as a result of harvesting the kinetic energy during vehicle damping events.

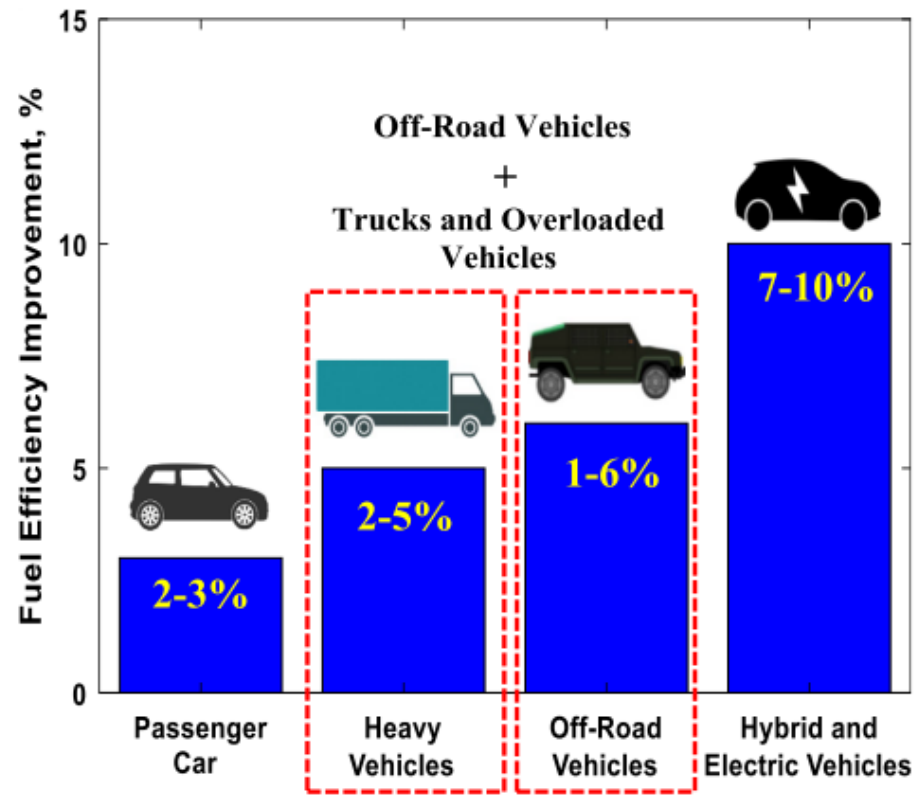

Fig. 1. Fuel saving from energy-harvesting during vehicle damping events [38; 60]

As shown in Fig. 1, off-road vehicles, heavy trucks and heavy duty vehicles have a greater potential for fuel savings of up to $6 \%$, while passenger cars may show lower savings to $3 \%$. This is due to higher 
levels of vibration intensity. Therefore, the energy recovery systems should primarily be of interest to fleet customers.

The key element that converts vibration energy into electricity is the energy receiving shock absorber. It mainly contains two components: energy conversion (a linear or rotary electric motor) and transmission devices (from reciprocation to rotation) [58]. Accordingly, the vibration energy flows into the suspension making the damper moves vertically up and down sequentially. The electrical power could be generated out of these perpendicular oscillations directly by the linear electromagnetic harvesters, or indirectly by the rotary electromagnetic harvesters [54]. The general layout of different electromagnetic regenerative dampers is shown in Fig. 2.

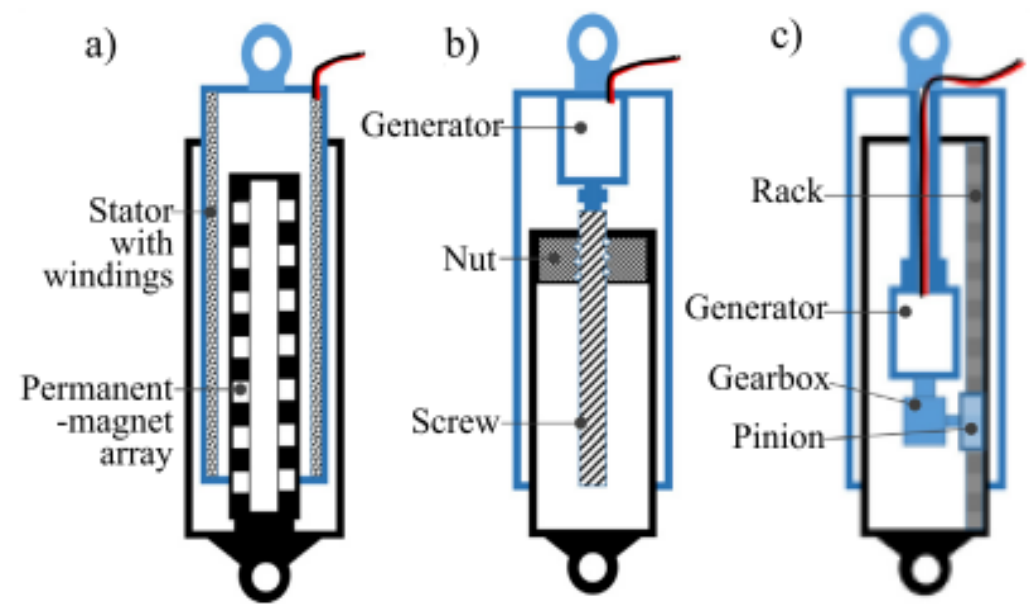

Fig. 2. General layout of different electromagnetic regenerative dampers [58]:

$\mathrm{a}$ - linear motor; $\mathrm{b}$ - ball screw; $\mathrm{c}$ - rack-pinion

Zhang et al. [58], obtained an average regenerative power of $110.6 \mathrm{~W}$, used the electro-hydraulic energy harvesting damper on off-road vehicles. However, they showed that a compromise is necessary between energy harvesting and the damping characteristics of a shock absorber. The work of Li et al. [37] presented the design of the energy-receiving shock absorber and optimization of the control circuit, as shown in Fig. 3. The shock absorber architecture mainly consists of a motor and a ball-screw, which is used to convert vibrations between the vehicle body and chassis into rotary motion of the motor. The electric motor acts as a generator to convert the kinetic energy of the suspension into electric energy stored in a battery for further usage, while providing a damping force [37].

a)

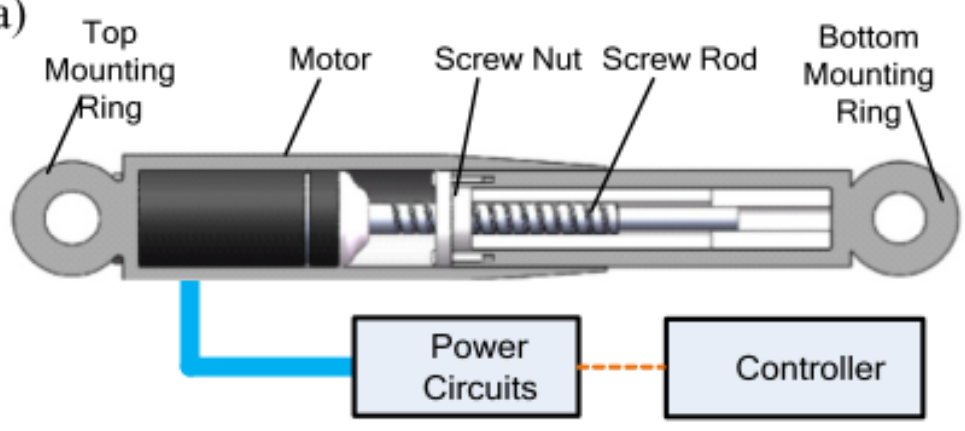

b)

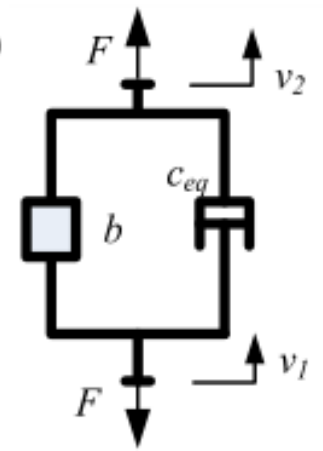

Fig. 3. Scheme of the shock absorber ball-screw structure (a) and the equivalent dynamic model (b) [37]

Due to the impact of the moment of inertia of the motor rotor and screw rod, the energy-harvesting shock absorber can be regarded as a conventional oil damper connected by an inerter in parallel, as shown in Fig. 3. b) [61]. $F$ is the total force of the shock absorber, $v_{1}$ and $v_{2}$ are the velocities of the vehicle body and chassis respectively, $b$ - the inerter value, $c_{e q}$ is the equivalent damping coefficient. The PMSM generator (permanent magnet synchronous motor) and a buck-boost converter used to collect energy gave positive results. The results showed that the proposed control circuit and control strategy were characterized by a high response speed of $4 \mathrm{~Hz}$ and a small tracking error of $6.44 \%$ 
compared with the pre-set damping coefficient value, which establishes a good foundation for the future study of energy-harvesting semi-active suspension [37]. Additionally, high energy collection efficiency of $40.72 \%$ to $70.55 \%$ was obtained from the suspension tested with sinusoidal excitation and accidental road excitation.

As shown by Abdelkareem et al. [54], from vehicle vibrations caused by road unevenness, an average power of $350 \mathrm{~W}$ can be obtained for a medium-sized sedan (using four energy-absorbing shock absorbers). For larger vehicles, harvesting power can be significantly higher. Electromagnetic regenerative damper has a relative low load carrying capacity, therefore it is more suitable for minivans and passenger cars etc. Electro-hydraulic damper can provide a higher damping force, which is usually required by off-road vehicles. Therefore, there is a great potential to recover the energy lost from vehicles, which can be used to power, e.g., systems that increase the comfort of traveling. More information on the design of waste energy recovery system in the vehicle suspension system can be found in the following literature: $[13 ; 57 ; 58 ; 59 ; 62]$. Fig. 4 shows the location of the energy harvesting shock absorber in the rear axle of the vehicle.
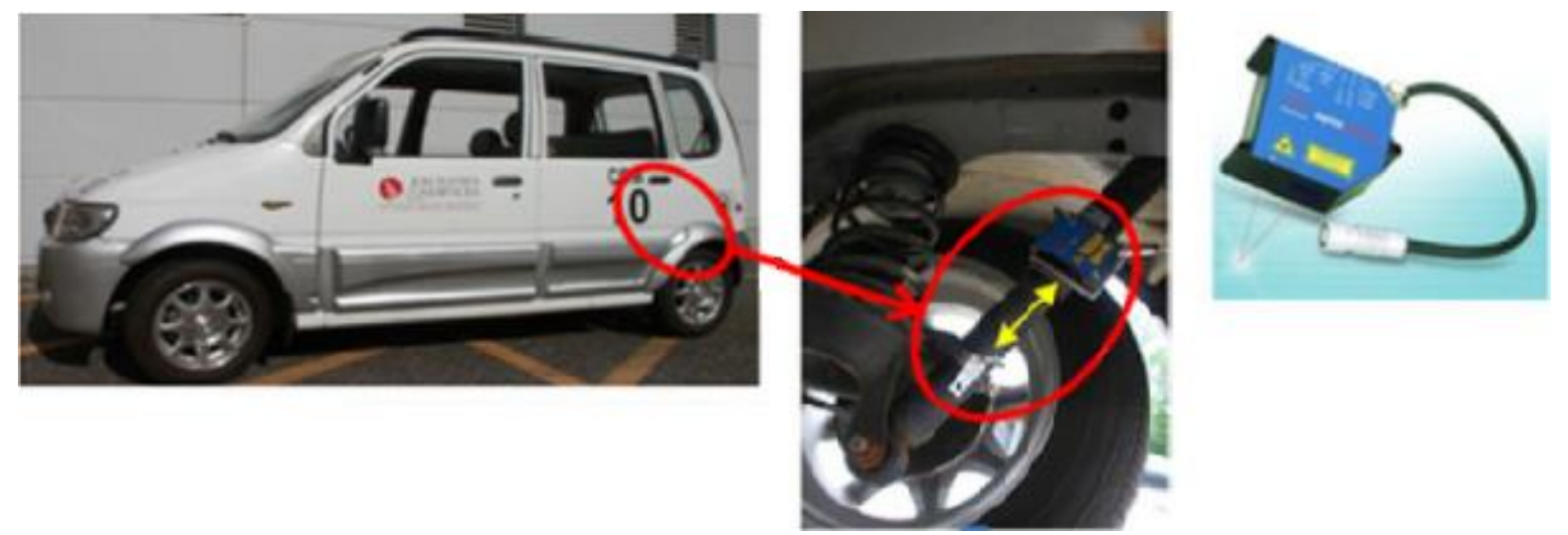

Fig. 5. Place of installation of the energy harvesting shock absorber [57]

Unlike small-scale energy harvesting, such as wireless sensors and electronic devices, systems based on recovering energy from a car's internal combustion engine suspension have not been sufficiently researched. Initial research on energy recovery from the displacement of a working compression ignition engine in an off-road passenger vehicle is presented in [45]. The authors believe that there is a potential for partial recovery of energy from a vehicle's internal combustion engine suspension system during operation with a piezoelectric system. The subject of the research was the following: a passenger all-terrain vehicle UAZ-31512 with a 4-cylinder in-line supercharged diesel engine - 2.5TD with direct injection used in Land Rover Discovery 200 series. Fig 5 shows the measuring circuit for engine displacement and mounted energy piezoelectric harvesting system on the engine block. The results of the output voltage from experiments are present in Fig. 6.

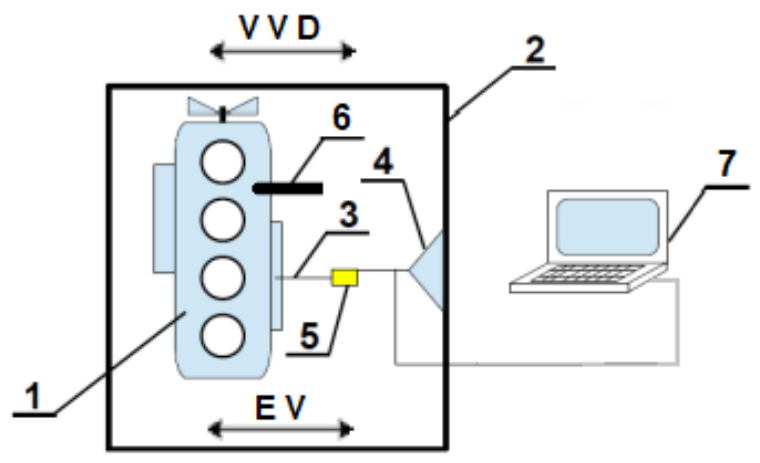

Fig. 5. Measuring circuit: 1 - Diesel engine; 2 - vehicle body; 3 - potentiometer arm; 4 - load-bearing structure; 5 - linear potentiometer; 6 - piezoelectric energy harvester;

7 - computer; VVD - vehicle's vibrations during driving; EV - horizontal engine vibrations

Comparing the linear (with impacts) cases with the non-linear (with impacts), it can be concluded that there is an effect of a higher output voltage in the second case. It is worth noting that by impacts 
there the damping effect is smaller; the corresponding root mean square of the voltage output is 0.1020 and 0.1325 RMS (voltage) for linear and non-linear energy harvesters, respectively. Impacts of the beam over the amplitude limiter cause oscillations of a higher level, concerning the linear solution there is a dissipation of oscillations [45] (see Fig. 6).
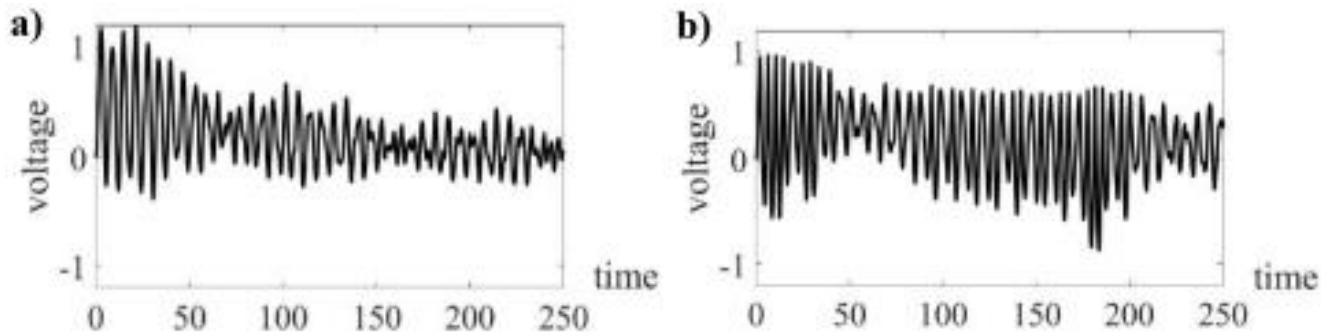

Fig. 6. Comparison results of output voltage for linear (a) and non-linear (b) case

Summarized in these experiments, not much difference in performance is found in terms of average induced voltage between the applied duty cycles, but this preliminary study gives the guidelines to prepare further research by changing the design of the energy harvesting system.

\section{Conclusions}

1. Based on the presented solutions for energy harvesting from the vehicle suspension systems, it can be concluded that better results were obtained for larger vehicles. Therefore, it is more practical to test electro-hydraulic shock absorbers for SUV's, off-road vehicles, heavy trucks, mining vehicles, military vehicles and engineering machines that are heavy and operated under poor road conditions.

2. As the research shows, it is possible to obtain the value of regenerative power at the level of several hundred watts. The lowest results are obtained for passenger cars driving on good quality roads (3 $\mathrm{W})$. The research shows that it is possible to obtain the value of the recovery power at the level of several hundred watts, on average, about $150 \mathrm{~W}$ for passenger cars and from 100 to $400 \mathrm{~W}$ for offroad vehicles, depending on the type of the road on which it is traveling. A worse road category results in a greater work of the suspension system and gives better results of the regenerated power.

3. The possibilities of energy recovery from the suspension system of the internal combustion engine in a vehicle are presented. Initial results have shown the potential for energy recovery in this area, but it requires further in-depth research. The author plans further research in this field. Due to the operating characteristics of internal combustion engines in an in-line configuration, it is worth taking an interest in engines with 4 or 3 cylinders.

4. Eenergy harvesting systems should be of particular interest to fleet customers, where a few percent benefits in reducing the fuel consumption lead to specific amounts of savings.

\section{Acknowledgements}

This publication was supported by the program of the Polish Ministry of Science and Higher Education under the project P)DIALOG DIALOG 0019/DLG/2019/10 in the years 2019-2021.

\section{References}

[1] Sommerauerová D., Chocholač J., Urbanova K. Sustainable green city logistic solution for the Prague agglomeration and retail chain. Perner's Contacts, 15(2), 2020.

[2] Droździel P., Tarkowski S., Rybicka I., Wrona R. Drivers' reaction time research in the conditions in the real traffic. Open Engineering, vol. 10, 1, 2020, pp. 35-47.

[3] Cernicky L., Kalasova A., Mikulski J. Simulation software as a calculation tool for traffic capacity assessment. Communications - Scientific Letters of the University of Zilina, vol. 18, 2, 2016, pp. 99-103.

[4] Stopka O., Stopkova M., Kampf R. Application of the operational research method to determine the optimum transport collection cycle of municipal waste in a predesigned urban area. Sustainability, vol. 11, 8, 2019, 2275. 
[5] Figlus T., Szafraniec P., Skrucany T. Methods of measuring and processing signals during tests of the exposure of a motorcycle driver to vibration and noise. International Journal of Environmental Research and Public Health, vol. 16, 17, 2019, 3145.

[6] Verner J., Sejkorova M., Veselik P. Volatile organic compounds in motor vehicle interiors under various conditions and their effect on human health. Scientific Journal of Silesian University of Technology. Series Transport. 107, 2020, pp. 205-216.

[7] Kuranc A., Słowik T., Wasilewski J., Szyszlak-Bargłowicz J., Stoma M., Šarkan B. Emission of particulates and chosen gaseous exhausts components during a diesel engine starting process. 9th International Scientific Symposium on Farm Machinery and Process Management in Sustainable Agriculture, Lublin, Poland. NOV. 22-24, 2017, pp. 210-215.

[8] Lizbetin J., Stopka O., Kurenkov P.V. Declarations regarding the energy consumption and emissions of the greenhouse gases in the road freight transport sector. The Archives of Automotive Engineering - Archiwum Motoryzacji, vol. 83, 1. 2019, pp. 59-72.

[9] Smigins R. Ecological impact of CNG/gasoline bi-fuelled vehicles. Book Series: Engineering for Rural Development Edited by: Malinovska, L; Osadcuks, V. $16^{\text {th }}$ International Scientific Conference: Engineering For Rural Development, Jelgava, Latvia, May 24-26, 2017, 2017, pp. 128 133.

[10] Flekiewicz M., Kubica G. The influence of selected gaseous fuels on the combustion process in the SI engine. Transport Problems, vol. 12, is. 3, 2017, pp. 135-146.

[11]Longwic R., Sander P., Zdziennicka A., Szymczyk K., Jańczuk B. Combustion process of canola oil and n-hexane mixtures in dynamic diesel engine operating conditions. Applied Sciences, vol. $10,1,2020,80$.

[12] Gutarevych Y., Shuba Y., Matijosius J., Karev S., Sokolovskij E., Rimkus A. Intensification of the combustion process in a gasoline engine by adding a hydrogen-containing gas. International Journal of Hydrogen Energy, vol. 43, 33, 2018, pp. 16334-16343.

[13] Pukalskas S., Kriaučiūnas D., Rimkus A., Przybyła G., Droździel P., Barta D. Effect of hydrogen addition on the energetic and ecologic parameters of an SI engine fueled by biogas. Applied Sciences, vol. 11, 2, 2021, 742.

[14] Górski K., Smigins R. Selected physicochemical properties of diethyl ether/rapeseed oil blends and their impact on Diesel engine smoke opacity. Energy and Fuels, vol. 32, 2, 2018, pp. 1796-1803.

[15] Szpica D. Validation of indirect methods used in the operational assessment of LPG vapor phase pulse injectors. Measurement, vol. 118, 2018, pp. 253-261.

[16] Aboltins A., Berjoza D., Pirs V. Theoretical model of exploitation of automobiles operated with bioethanol-gasoline mixtures fuels. $9^{\text {th }}$ International Scientific Conference: Engineering for Rural Development, Proceedings, Jelgava Latvia, May 27-28 2010. Edited by: Malinovska L., Osadcuks V. Engineering for Rural Development, 2010, 133-138.

[17] Kucera M., Kopcanova S., Sejkorova M. Lubricant analysis as the most useful tool in the proactive maintenance philosophies of machinery and its components. Management Systems in Production Engineering vol. 28, 3, 2020, pp. 196-201.

[18]Zając G., Węgrzyn A. Analysis of work parameters changes of diesel engine powered with diesel fuel and FAEE blends. Eksploatacja i Niezawodnosc, vol. 38, 2, 2008, pp. 17-24.

[19] Górski K., Smigins R. Impact of ether/ethanol and biodiesel blends on combustion process of compression ignition engine. Engineering for Rural Development, 2011, pp. 260-265.

[20] Rimkus A., Matijosius J., Rayapureddy S.M. Research of energy and ecological indicators of a compression ignition engine fueled with diesel, biodiesel (RME-Based) and isopropanol fuel blends. Energies, vol. 13, 9, 2020, 2398.

[21] Mikulski M., Wierzbicki S. Validation of a Zero-dimensional and two phase combustion model for dual-fuel compression ignition engine simulation. Thermal Science, vol. 21, 1, 2017, pp. 387-399. Part B.

[22] Verner J., Sejkorova M. Comparison of CVS and PEMS measuring devices used for starting $\mathrm{CO}_{2}$ exhaust emissions of light-duty vehicles during WLTP testing procedure. $17^{\text {th }}$ International Scientific Conference: Engineering For Rural Development, Jelgava, Latvia, May 23-25, 2018, pp. 2054-2059. 
[23] Bazhynova T., Kravchenko O., Barta D., Haievy, O., Pavelcik V. Neural network model of assessing the technical condition of the power unit of a hybrid vehicle. $12^{\text {th }}$ International ScienceTechnical Conference Automotive Safety, Automotive Safety 2020, 9293504.

[24] Danilov I., Popova I., Moiseev Y. Analysis and validation of the dynamic method for diagnosing diesel engine connecting rod bearings. Transport Problems, vol. 13, 1, 2018, pp. 123-133.

[25] Synak F., Kučera M., Skrucany T. Assessing the energy efficiency of an electric car. Communications - Scientific Letters of the University of Zilina, vol. 23, 1, 2021, pp. A1-A13.

[26] Skrucany T., Kendra M., Stopka O., Milojević, S., Figlus, T., Csiszár, C. Impact of the electric mobility implementation on the greenhouse gases production in Central European countries. Sustainability, vol. 11, 18, 2019, 4948.

[27] Tomasikova M., Tropp M., Gajdosik T., Krzywonos L., Brumercik F. Analysis of transport mechatronic system properties. Procedia Engineering, vol. 192, 2017, pp. 881-886.

[28]Eliasz J., Osipowicz T., Abramek K.F., Matuszak Z., Mozga L. Fuel pretreatment systems in modern CI engine. Catalysts, vol. 10, 6, 2020, 696.

[29] Szpica D., Kusznier M. Model evaluation of the influence of the plunger stroke on functional parameters of the low-pressure pulse gas solenoid injector. Sensors, vol. 21, 2021, 234.

[30] Wierzbicki S. Evaluation of the effectiveness of on-board diagnostic systems in controlling exhaust gas emissions from motor vehicles. Diagnostyka, vol. 20, 4, 2019, pp. 75-79.

[31] Figlus T. A method for diagnosing gearboxes of means of transport using multi-stage filtering and entropy. Entropy, vol. 21, 3, 2019, 441.

[32] Jedliński Ł., Jonak J. A disassembly-free method for evaluation of spiral bevel gear assembly. Mechanical Systems and Signal Processing, vol. 88, 2017, pp. 399-412.

[33] Karioja K., Lahdelma S., Litak G., Ambrożkiewicz B. Extracting periodically repeating shocks in a gearbox from simultaneously occurring random vibration. 15th International Conference on Condition Monitoring and Machinery Failure Prevention Technologies, CM/MFPT 2018, pp. 456464.

[34] Szydło K., Wolszczak P., Longwic R., Litak G., Dziubiński M., Drozd A. Assessment of lift passenger comfort by the Hilbert-Huang transform. Journal of Vibrational Engineering and Technologies, vol. 8(2), 2020, pp. 373-380.

[35] Marichal G.N., Del Castillo M.L., López J., Padrón I., Artés M. An artificial intelligence approach for gears diagnostics in AUVs. Sensors, vol. 16, 2016, 529.

[36] Brumercik F., Lukac M., Caban J. Unconventional powertrain simulation. Communications Scientific Letters of the University of Zilina, vol. 18, 2, 2016, pp. 30-33.

[37]Li S., Xu J., Pu X., Tao T., Mei X. A novel design of a damping failure free energy-harvesting shock absorber system. Mechanical Systems and Signal Processing, vol. 132, 2019, pp. 640-653.

[38]Zhang Y., Guo K., Wang D., Chen C., Li X. Energy conversion mechanism and regenerative potential of vehicle suspensions. Energy, vol. 119, 2017, pp. 961-970.

[39] Faraj R., Graczykowski C., Holnicki-Szulc J., Knap L., Senko J. Adaptable pneumatic shockabsorber. $8^{\text {th }}$ Conference on Smart Structures and Materials, SMART 2017 and $6^{\text {th }}$ International Conference on Smart Materials and Nanotechnology in Engineering, SMN 2017, 2017, pp. 86-93.

[40] Maloch M., Cornak S. Specific aspects of active and semi-active suspensions. 17 ${ }^{\text {th }}$ International Scientific Conference: Engineering For Rural Development, Jelgava, Latvia, May 23-25, 2018, pp. 2104-2109.

[41] Choi Y., Negash A., Kim T.Y. Waste heat recovery of diesel engine using porous medium-assisted thermoelectric generator equipped with customized thermoelectric modules. Energy Conversion and Management, vol. 197, 2019, 111902.

[42] Vale S., Heber L., Coelho P.J., Silva C.M. Parametric study of a thermoelectric generator system for exhaust gas energy recovery in diesel road freight transportation. Energy Conversion and Management, vol. 133, 2017, pp. 167-177.

[43] Itani K., De Bernardinis A., Khatir Z., Jammal A. Comparative analysis of two hybrid energy storage systems used in a two front wheel driven electric vehicle during extreme start-up and regenerative braking operations. Energy Conversion and Management, vol. 144, 2017, pp. 69-87.

[44] Labuda R., Barta D., Kovalcik A. Effective use of the braking effect of vehicle drivetrain at deceleration. 41st International Scientific Conference of Czech and Slovak University Departments 
and Institutions Dealing with the Research of Internal Combustion Engines (KOKA 2010), 2010, pp. 206-211.

[45] Caban J., Litak G., Ambrożkiewicz B., Gardyński L., Stączek P., Wolszczak P. Impact-based piezoelectric energy harvesting system excited from diesel engine suspension. Applied Computer Science, vol. 16, no. 3, 2020, pp. 16-29.

[46] Giri A.M., Ali S.F., Arockiarajan A. Dynamics of symmetric and asymmetric potential well-based piezoelectric harvesters: A comprehensive review. Journal of Intelligent Material Systems and Structures, 2020, pp. 1-67.

[47] Jettanasen C., Songsukthawan P., Ngaopitakkul A. Development of micro-mobility based on piezoelectric energy harvesting for smart city applications. Sustainability, vol. 12, (7), 2020, 2933.

[48] Sarker M.R., Julai S., Sabri M.F., Said S.M., Islam M.M., Tahir M. Review of piezoelectric energy harvesting system and application of optimization techniques to enhance the performance of the harvesting system. Sen. Actuators A Phys., 300, 2019, pp. 1116-1134.

[49] Chalioris C.E., Karayannis C.G., Angeli G.M., Papadopoulos N.A., Favvata M.J., Providakis C.P. Applications of smart piezoelectric materials in a wireless admittance monitoring system (WiAMS) to structures - tests in RC elements. Case Stud. Constr. Mater. vol. 5, 2016, pp. 1-18.

[50] Micek P., Grzybek D. Wireless stress sensor based on piezoelectric energy harvesting for a rotating shaft. Sen. Actuators A Phys. vol. 301, 2019, pp. 1117-1144.

[51] Hadas Z., Janak L., Smilek J. Virtual prototypes of energy harvesting systems for industrial applications. Mechanical Systems and Signal Processing, 110, 2018, pp. 152-164.

[52] Ma Y., Chen J., Zhu X., Xu Y. Lateral stability integrated with energy efficiency control for electric vehicles. Mech. Syst. Signal Process. vol. 127, 2019, pp. 1-15.

[53]Zhang X., Göhlich D., Li J. Energy-efficient toque allocation design of traction and regenerative braking for distributed drive electric vehicles. IEEE Trans. Veh. Technol. 67, 1, 2018, pp. 285-295.

[54] Abdelkareem M.A.A., Xu L., Ali M.K.A., Elagouz A., Mi J., Guo S., Liu Y., Zuo L. Vibration energy harvesting in automotive suspension system: A detailed review. Applied Energy, vol. 229, 2018, pp. 672-699.

[55]Zou J., Guo X., Abdelkareem M.A.A., Xu L., Zhang J. Modelling and ride analysis of a hydraulic interconnected suspension based on the hydraulic energy regenerative shock absorbers. Mechanical Systems and Signal Processing, vol. 127, 2019, pp. 345-369.

[56] Julien C., Mauger A., Vijh A., Zaghib K. Lithium Batteries. Lithium Batteries, Springer International Publishing, 2016, pp. 29-68.

[57]Zuo L., Zhang P.S. Energy harvesting, ride comfort, and road handling of regenerative vehicle suspensions. Journal of Vibration and Acoustics, Transactions of the ASME, vol. 135, 1, 2013, 011002 .

[58]Zhang Y., Chen H., Guo K., Zhang X., Eben Li S. Electro-hydraulic damper for energy harvesting suspension: modeling, prototyping and experimental validation. Applied Energy, vol. 199, 2017, pp. 1-12.

[59] Li C., Zhu R., Liang M., Yang S. Integration of shock absorption and energy harvesting using a hydraulic rectifier. Journal of Sound and Vibration, vol. 333, 17, 2014, pp. 3904-3916.

[60] Abdelkareem A.A.M., Eldaly A.B.M., Ali M.K.A., Youssef I.M., Xu L. Monte Carlo sensitivity analysis of vehicle suspension energy harvesting in frequency domain. Journal of Advanced Research, vol. 24, 2020, pp. 53-67.

[61] Guo S., Liu Y., Xu L., Guo X., Zuo L. Performance evaluation and parameter sensitivity of energyharvesting shock absorbers on different vehicles, Vehicle System Dynamics, vol. 54, 7, 2016, pp. 918-942.

[62] Xie L., Li J., Li X., Huang L., Cai S. Damping-tunable energy-harvesting vehicle damper with multiple controlled generators: design, modeling and experiments. Mechanical Systems and Signal Processing, 99, 2018, pp. 859-872. 